\title{
Translation of Personification and Suspension of Disbelief
}

\author{
Mitra Shahabi \\ University of Aveiro, Portugal \\ Maria Teresa Roberto \\ Department of Language and Culture, University of Aveiro, Campus \\ Universitário de Santiago, 3810-193, Aveiro, Portugal
}

Received: 12-01-2015

doi:10.7575/aiac.ijclts.v.3n.2p.1
Accepted: 25-02- 2015

Published: 01-04- 2015

\begin{abstract}
This study calls the translators' attention to animal personification in texts where in some cases the image of the animal is not only different from or contradictory to those in the target language but also different from or contradictory to those in the source text. The proposed translation strategies in this study are based on the specificity of the situations. The translator must reflect on three factors: a) the features of the animal in the source text, b) the image of that animal in the source language, and also c) its image in the target language. However, in this study, we conclude that the burden is put on the readers, rather than on the author or translators. They make use of the reader's willing suspension of disbelief which helps them in encountering breakdown in established conventions and norms, to "suspend" their disbelief about odd or eccentric entities and concepts.
\end{abstract}

Keywords: shared assumption, translation cognitive approach, cognitive equivalence, disbelief suspension

\section{Introduction}

\subsection{Translation of Personification}

Personification is a special subtype of metaphor, where animals or objects are specified as being a person, as in example (1), where pig describes Mr. Johns as a deceiver.

(1) Mr. Johns deceived all of us. The pig does not intend to stop this attitude.

We noticed that while metaphor has received a great deal of consideration, from among different types of figure of speech, personification, to the best of our knowledge, has not been studied extensively enough; no specific study has been carried out in the field of its translation difficulties and no specific strategy has been introduced for its translation in particular. It seems that personification is not considered a problem of translation and has been more or less ignored by the translators. However, it should be noticed that this kind of figure of speech is usually one word, and for the readers encountering single-word metaphors in a text, it is unlikely think they might bear non-literal sense and this may lead to an interpretation that is different from the intended one.

For non-single-word metaphors, the sense of the metaphor can be discovered at least by guessing from the context. The context and the author's and reader's shared assumption help to understand what characteristic and attribute is mapped from one domain (source domain) onto the other domain (target domain) and consequently understand the metaphorical meaning. For example, for the Persian metaphor the prisoner is a barking dog, here the target domain (the prisoner's behavior) is understood by that aspect of the source domain $(\log )$ which is defined by the context (barking). The dog is not considered the final target domain, rather the barking dog is, because dog represents general correspondences for the source domain but barking dog is just 'an angry and aggressive sound'; consequently, the nonfigurative meaning is: 'the prisoner is angrily shouting'. Regarding translation from language 1 (L1) into language 2 (L2), in which this metaphor does not exist, a possible translation can be 'the prisoner is angry like a barking $\operatorname{dog}^{\prime}$. In case of personification, if a reader encounters $d o g$ as a personified character in the text, there is no immediate context which can help the reader to perceive the metaphorical meaning of the animal. Consequently, if the figurative meaning of the animal in the two languages in question is different and if the animal term is translated without any change in the name of the animal or adding some description or explanation, there is a strong tendency for the reader to view the animal in terms of the figurative meaning in his/her own language; s/he will misinterpret. For, there may be a contradiction between the reader's expectation of the animal personification and how the animal has been described in the text. Therefore, the translation of animal personification seems much more challenging in comparison with the translation of animal metaphors.

Beside the notion of single-word metaphor, it is common knowledge that culture-bound expressions need careful analysis in translation. It is obvious that differences between different cultures create some variations in the use of personification and may lead to misinterpretations or problems in translating figures of speech. Owl in English, as an 
example, is personified as being 'wise' while in Persian it is believed to be 'ominous'; therefore, translators should pay attention to these differences.

The focus of this study is on translation of animal personification. As animals are productively used in the metaphorical conceptualization of abstract human characteristics (Lakoff \& Johnson, 1980), the subject matter of this study was constricted to animal personifications. In what follows we tried to find what strategies can be implemented in the translation of animal personifications.

\subsection{The Hypothesis and the Applies Strategy}

Regarding the translation of animal personification, we could, at the onset, propose that if an animal name in L1 does not have the same personification in L2, in the case of translation, the animal term should be changed to an animal name in L2 which has the same figurative meaning as L1. Otherwise, readers can interpret the metaphor in a different or even contradictory way from the one intended by the L1 author. Therefore, the translator should be equipped with enough knowledge in recognizing the source language (SL) associative meanings which are unknown to the target language (TL) readers in order to be able to resolve the problem of misunderstanding and misinterpretation for the target readers. The problem of misinterpretation cannot be easily solved; but contrastive studies of culture can pave the way by anticipating and simplifying the potentially problematic cases. With regard to the differences between the metaphorical expressions of different societies, contrasting their constitutive metaphorical concepts (the first phase of study) seems an appropriate framework for the translation of metaphorical expressions.

To attain the goal, George Orwell's Animal Farm (1945) was studied. A novel with animal characters was considered one of the best examples of animal personification. A comparison between animal features in Animal Farm (AF) and the English and Persian readers' expectations of the animals attitudes was carried out. It was expected that this comparison show whether the readers expect the same traits in the animals in English and Persian or if their expectations are different.

Afterwards, $A F$ was investigated along with its six translations into Persian, in order to address the appropriateness of the translations regarding animal personifications. A series of possible different situations of translation were pointed out and discussed as a set of generalizable techniques in translating personification with the aim of removing particular problems posed on translators when they encounter culture-specific animal metaphors or personification. The goal is to aid translators in preventing mistranslation.

\subsection{The Rationale behind Choosing English and Persian Languages for this Study}

The rationale behind choosing the two languages of English and Persian was to provide a comparison between English metaphorical meaning of animals with Persian as a "high-context culture", where the English language is perceived as being a "low context language" (Hall, 1976). As Hall (1976) puts it, high-context cultures tend to be more common in the Asian cultures than in European. In high-context cultures, words are not so important as context; the words and phrases usually are understood by means of cultural context rather than a textual context. In this case, when one says one word, the interlocutor understands ten. Communication is usually carried out based on shared assumption of the speaker/writer and the listener/reader. These assumptions are very strongly entangled with history and tradition and they usually change a little over time. In contrast, low-context cultures tend to be more explicit, the things are fully spelled out. Accordingly, interaction between these two communities can be problematic and it should not be overlooked by translators.

We postulated that as Persian is considered a high-context culture, it would be interesting if we carry out a comparison between this language and English as a lower-contex culture. We assumed that the further the context cultures are, the higher the difference between the metaphorical meaning of their animal metaphors and personifications will be.

\subsection{Review of Literature}

As indicated above, to the best of our knowledge, no specific study has been allocated to the translation difficulties or strategies of animal personification. Therefore, we tried to discover if some aspects of metaphor translation strategies can provide a special model for the translation of animal personification.

Different theorists have approached metaphor translation from different viewpoints. In the literature, metaphor translating centers around three stands: procedures of transfer, text typologies, and cultural specificity.

Dagut (1976) states that there seems to be "two diametrically opposed views" on the translatability of metaphors (p.25). On the one hand, some theorists' arguments are in favor of translatability of metaphor and supporting the word-forword method, and on the other hand, there are those who find metaphors untranslatable. Newmark's (1980) view seems to be somewhere between these opposed views and presents the following methods in translating metaphors, based on the categorization of metaphors in five types of dead, cliché, stock, original, and recent (pp.88-91):

a) Literal translation; Reproducing the same image in the TL (for dead and original metaphors)

b) Replacing the image in the SL with a standard TL image or reducing it to sense (for clichés)

c) Translation of metaphor by simile (weakened metaphor)

d) Translation of metaphor by simile plus sense

e) Translation of metaphor by simile plus sense

f) Conversion of metaphor to sense (for stock/standard metaphors)

g) Deletion 


\section{h) Same metaphor combined with sense}

Several criticisms are addressed to such a view of metaphor translating. Maalej (2008), for example, states "although the scheme tries to specify the procedure corresponding to each type of metaphor, the correspondences are not universally applicable" (p. 61). Toury (2000) believes that what is important is not the classification of metaphors, but rather the process and placement of metaphors. He refers to three main categories: translation of metaphor into the same metaphor; translation of metaphor into a different metaphor; and translation of metaphor into a non-metaphor. He also suggests an alternative: deletion.

Newmark (1980) takes another view when he states translation of metaphor depends on the text we are rendering. In expressive texts, for example, metaphors are of low translatability since these texts carry a heavy load of 'contextual, semantic and pragmatic information'. In contrast, "in informative texts, where they have no real functional relevance informatively speaking, lexicalized metaphors are of high translatability, and might as well be ignored in the translational process" (quoted by Maalej, 2008, p.62).

His theory is not supported by some theorists. They believe that the text-type is important in defining the method of translating a metaphor but the status of metaphor on the typology scale is not clear; "where a metaphor is situated on typology scale it cannot be determined by a system of watertight categories: its position shifts with cultural developments" (Snell-Hornby, 1995, p.57). Second, as Hatim (1997, p.10) argues, "texts can never be so neatly categorized and are often found to display characteristics of more than one type." It is not possible to define a text as being purely informative, expressive, or vocative.

In the non-cognitive tradition, many claim that in the translation of metaphor, culture should be regarded as center of focus (Nida 1964; Catford 1965; Dagut 1987; Mason 1982; Snell-Hornby 1995; Quinn 1991). As different cultures conceptualize experience in different ways, metaphor is a culture-specific phenomenon. In this regard, Mason (1982) determines that if a translator ignores culture-specific features of metaphors, in another word, de-culturalizes the metaphor, the reader will be "deprived of much information of great value about the SL culture." (p.144).

Our argument concludes in favor of Dagut (1976) who claims that for translation of metaphor there is no simplistic general rule but its translatability depends on two factors: “(1) The particular cultural experiences and semantic associations exploited by it, and (2) the extent to which these can, or cannot, be reproduced non-anomalously in TL, depending on the degree of 'overlap' in each particular case" (p. 32). Therefore, Dagut (1987, p.81) rightly argues that "the untranslatability of metaphor is due to the absence of the cultural reference of a SL metaphor in the TL, the cultural and lexical specifics of the SL, or simply compactness of lexical items."

\subsubsection{Cognitive Approach in Translation of Metaphor}

All the above mentioned studies of metaphor translation "shy away from the exploration of the continuous connection of metaphors as mental or picturesque representations of the real world and the language used to realize these pictures in words". (Al-Hasnawi 2007. P.2)

In the translation of metaphor the translators should concern themselves with the cultural associations and patterns of thinking of the two communities of the SL and the TL. In this case, Katan (1999) points out in translating a text to a language of any culture one should be aware of the form of things that people have in their minds, their models for perceiving, relating to, and interpreting them. In other words, the translator should first try to understand how SL readers "perceive the world and structure their experience" and then try "to accommodate his text to the experience of the target-language reader, and to the way it is re-coded in the TL" (Al-Hasnawi, 2007). For this purpose, "metaphors must be looked at as cognitive constructs representing instances of how people conceptualize their experiences, attitudes and practices, and record them" Al-Hasnawi's (2007). Al-Hasnawi adds "since metaphor is shaped by the socio-cultural beliefs and attitudes of a specific culture, the translation of this linguistic phenomenon should be based on the 'cognitive equivalence'."

Al-Hasnawi's (2007) argumentation is in favor of a cognitive approach in the translation of metaphors. We also believe the cognitive approach is the most viable and effective means to decrease the degree of loss in the translation of metaphors. This approach formed the main focus of the present research as well due to the fact that it approaches the two outstanding issues of text-typology and culture-specificity.

The problem is that, according to Maalej (2008), "owing to the relative youth of cognitive linguistics in general, and the contemporary theory of metaphor in particular", most of the theories and models of translation of metaphor, "just point to the relevance of cognitive operations and abilities in translating metaphor."

\subsubsection{Mapping Conditions}

In the cognitive view of metaphor translation, Maalej (2008, p.64) refers to three cognitive steps:

a) Unpacking the SL linguistic metaphors into their conceptual counterparts

b) Comparing cultures by determining whether linguistic and conceptual metaphors across-cultures show a similar mapping condition' or a 'different mapping condition

c) Re-packing the TL conceptual and linguistic counterparts according to the experiential practices of the TL

Mandelblit (1995) offers the cognitive translation hypothesis in two assumptions: "similar mapping condition" (SMC) and "different mapping condition" (DMC). The SMC refers to a condition in which SL metaphors are mapped into a domain similar to that of the TL; the DMC, however, refers to a condition in which SL metaphors are mapped into a domain different from that of the TL. In this case, the translation becomes more difficult because the translator has to 
look for another conceptual mapping (i.e. another cognitive domain) that fits in the target language to the same extent as the cognitive domain does in the source language (Al-Hasnawi, 2007). SMC makes the translators' task easier and more successful because they are dealing with the same cognitive domain in the two languages involved in the translation, and their translation, according to Al-Hasnawi (2007), will appear as an equivalent TL metaphor or - under the worst conditions - a TL simile. However, in DMC the result can emerge in different forms: simile, paraphrase, footnote, an explanation or sometimes be deleted.

Mandelblit's (1995) proposal is too general to cover all specific situations. Hiraga (1991) offers a different hypothesis with four assumptions:

$>$ Similar metaphorical concepts and similar metaphorical expressions:

(2) English: History repeats itself.

Persian: تاريخ تكرار مى شود/tarikh tekrar mishavad/ (history repeats itself.)

$>$ Similar metaphorical concepts but different metaphorical expressions:

(3) English: A cat has nine lives.

Persian: سكَ جون است/sagjoon ast/ (he dies as hard as a dog.)

$>$ Different metaphorical concepts but similar metaphorical expressions: Owl, For example, represents a completely different picture in the two languages. $O w l$ in English portrays 'wisdom'. $O w l$ in Persian is 'inauspicious'.

$>$ Different metaphorical concepts and different metaphorical expressions: American English and Japanese do not share conceptual and linguistic metaphors conceptualizing 'ideas'. In American English, ideas are in the mind while in Japanese ideas are in hara (belly).

The proposed metaphor translation strategies, in a cognitive view, are summarized in an overall final statement that the translator's effort should be guided toward producing a similar metaphorical concept in the TT which is achieved, according to Maalej (2008), through unpacking the SL metaphors into their conceptual counterparts and re-packing the TL conceptual and linguistic counterparts according to the experiential practices of the TL. In case the mapping conditions of metaphors in both the ST and the TT are the same, the translation will result in a similar metaphorical expression in the TT and in case the mapping conditions of metaphors are not the same, usually a different metaphorical expression in the TT which has the same metaphorical meaning as in the ST is replaced. The attempt, based on the relevance theory of translation (Gutt, 2004), is to get the optimal relevance between the translation and the context by matching the ST author's intention with the cognitive environment of the reader (the mental environment when he/she processes a text).

\subsubsection{Cognitive View of Translation of Animal Personification}

Regarding translation of animal personification, that is in fact a single-word metaphor, where the animal metaphors are identical in the two languages, the task of translator is easy; keeping the same animal meets the goal. That is, the identical image is easily conveyed by choosing the same animal in the target text (TT). However, where the animal in the SL carries a different or opposite connotation in the TL, for example, an animal with a negative image in the SL, whose TL equivalent is positive, keeping the same animal in translation leads the TT reader to make false assumptions about the meaning. The translators should do their utmost to look for a proper pattern of translation in order to retain the same image of the source text in the (TT); as an example, horse in English can be replaced by cow in Persian where the sense of 'eating much' is represented by different animals in the two languages. This procedure preserves the animal image in the SL and fidelity is not jeopardized. Besides, the SL author's intention of the planned choice of animals, in accordance with their meanings in the SL culture, is understood by the TT reader. But it should be kept in mind that this strategy (replacement) in case of differences might be criticized for one shortcoming that is the TT readers will remain unfamiliar with the peculiarities and culture of the SL.

The pattern of replacement, modeled from metaphor translation strategies, can be proposed for rendering an animal with a different or opposite image in the TL. There are cases for which no equivalent may exist in the TL. Here, the three following methods, adjusted with metaphor translation strategies, may be suggested:

Translation of personification to simile: By this method, the animal remains the same in the TL and a proper modifier is added. Putting in another way, a word (mostly, an adjective) which contains and highlights the characteristics attributed to the animal in the SL is added to the animal term; hence, the animal term and the modifier structure the TT equivalent term. By adding a modifier to the SL entity the translator can prevent the reader from adding some specific connotations to the SL entity or creating different (unrelated or, even worse, contradictory) images from what the author of the original intended to convey. For example: I told the pig to look for a solution where pig refers to 'a clever person' in this text while in Persian this animal has no image of 'intelligence'; the ultimate image of pig in Persian is 'a wicked person'. Hence, the translator's task is to add the modifier 'clever' in order to prevent the TT reader from extracting the wrong interpretation. The output will be من به خوك زبيرك كفتم به فكر خاره باثند /man be khook-e zirak goftam be fekr-e chareh bashad/ (I told the clever pig to look for a solution).

Literal translation and explaining the ST personification in the footnote: Here, the animal remains the same in the TL and the animal metaphorical meaning in the ST is explained in the footnote. The strong point of this strategy is that the TT reader gets familiar with the SL cultural and metaphorical knowledge; however, it is criticized for causing interruption in the flow of the text. 
Conversion of personification to sense: Where the ST personification is different or does not exist in the TL, it might be substituted for the metaphorical meaning of the personification. The weak point of this strategy is that the author's intention of using a figure of speech (personification) instead of simply conveying his/her message through a nonfigurative expression is violated.

Regarding the abovementioned models of translation, we selected Orwell's $A F$ to see how the animals have been translated into Persian in order to address the appropriateness of the translations regarding animal personifications. In the following section, the applied materials and method for this study are explained.

\section{Method}

\subsection{Materials}

The materials supporting the study were gathered from 3 English and 3 Persian dictionaries. The English dictionaries which were employed were 'Speaking of Animals: A Dictionary of Animal Metaphors' by Palmatier (1995), 'Webster's Online Dictionary, Rosetta Edition' (2005), and 'Oxford Advanced Learner's Dictionary' (1993). The Persian dictionaries were فرهنى نامه جانوران در ادب فارسى (fahangname-ye janevaran dar adab-e farsi/ [dictionary of animals in

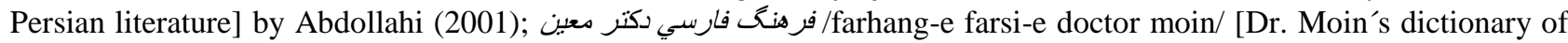
the Persian language] by Moin (1974), and فرهنك زبان فارسي ارسورز /farhang-e zaban-e farsi-e emroz/ [dictionary of the modern Persian language] by Sadri Afshar, et. al.(1990). The other source of study was the George Orwell's $A F$ (1945) along with its six Persian translations (two titled under مزرعه حيوانات/mazrae-ye heyvanat/ [the farm of animals] by Noorahmar (1983) and Hosseini and Nabizade (2003); and four titled as قلعه حيو/تات/Ghale-ye Heyvanat/ [the castle of animals] by Amirshahi (1982), Firoozbakht (1992), Akhondi (2004), and Jadidi and Mohammadi Asiabi (2004).

As we did not find any fully appropriate Persian dictionary like the English one, we felt it necessary to conduct a survey among Persian participants by means of questionnaires. The respondents were invited to write about the figurative meaning and use of animal terms used in $A F$, in their culture.

\subsection{Participants}

The respondents to the questionnaires were selected based on a stratified sampling. That is, we divided the participants into homogeneous subgroups based on "language/culture" and "education level". After we singled out this stratification we selected the participants randomly (a simple random sampling) within 3 pre-established groups (each consisting of 30 persons). Each group belonged to a different educational level: Basic, Secondary, and Higher. Accordingly, the Persian questionnaires were distributed among 90 Persian participants (30 basic, 30 secondary, and 30 higher). This number of contributors was considered sufficient to provide a grounding representation of a general group. The sampling stage was considered unnecessary.

\subsection{Procedures}

This research was a descriptive analysis. The first step was to make a list of the animals used in the $A F$ and the characteristics of the animals. These characteristics are determined after a complete study of the book, using what each animal does and how it behaves.

We made another comparison between English readers' expectations and the characteristics with which the animals were represented in $A F$. Although what was generally expected in this case was that there are no differences between English readers' expectations and the characteristics of the animals in $A F$, we looked for possible differences. We assumed that if we find any differences, then the strategy that is given for the translation of animal terms in the case of differences would be different.

The three English dictionaries were investigated. The information mentioned for every animal of the list in the dictionaries was studied and the personifying characteristics, if any, were written down and then represented in tables. The combination and the summary of all the three dictionaries was titled in the respective table under "the English readers' expectations".

The same procedure was followed for Persian, i.e. the Persian dictionaries were studied, and the personifying characteristics of each animal were represented in the tables. For Persian, there are also tables demonstrating the data collected from the responses to questionnaires. The questionnaires consisted of the name of the animals in $A F$. The respondents were asked to write for each animal as many personifying characteristics as they know along with some examples in forms of idioms, proverbs, or wise sayings for the purpose of discovering all the other characteristics probably new or not found in Persian dictionaries or among the personifying characteristics referred by the responders. Afterwards, the Persian information (from dictionaries and questionnaires) was put in the respective table under the title of "the Persian readers' expectations", a manifest of combination and the summary (carried out in the same manner as for English). This table helped to predict the expectations of the Persian readers about the personality of the animals when he/she is reading the $A F$ translations.

Afterwards, based on the comparison of animal cultural perceptions between the ST and the SL and also the representation of that animal in the TL, a series of possible different situations of translations were pointed out and discussed.

\section{Results}

Table 1 represents the characteristics attributed to the animals in $A F$. These characteristics have been determined after a complete study of the book, using what each animal does and how it behaves. Comma (,) separates the same attribution and slash $(/)$ separates the different ones. 
Table 1. Characteristics of animals in Animal Farm

\begin{tabular}{ll}
\hline Animals & \multicolumn{1}{c}{ Characteristics } \\
\hline Cat & $\begin{array}{l}\text { Disappearing during work-time, Reappearing at lunch-time, Staying away from any activity, Busy with her } \\
\text { own work }\end{array}$ \\
\hline Chickens & Small/ Weak \\
\hline Cows & Ordinary characters/ Victims \\
\hline Dogs & Guards/ Wild, Killers \\
\hline Donkey & $\begin{array}{l}\text { The worst-tempered/ Stubborn/ Never expressing any ideas, but not stupid/ Having a long life and } \\
\text { remembering every thing }\end{array}$ \\
\hline Ducklings & Offspring/ Innocent/ Unprotected \\
\hline Ducks & Gregarious / Victims/ Not intelligent \\
\hline Goat & Slow at learning \\
\hline Hens & Feminine/ Easily defeated/ Victims/ Submissive \\
\hline Horse & Most faithful disciple/ Dedicated hard-worker/ Strong/ Not intelligent \\
\hline Mares & Kind/ With maternal instincts/ Foolish \\
\hline Pigeons & Messengers \\
\hline Pigs & Cleverest animals of the farm, but with dirty behavior \\
\hline Rabbits & Wild, never tamed \\
\hline Rats & Wild, never tamed / Believed to be traitors \\
\hline Raven & Spy/ Tale-bearer/ A clever talker/ Hated by others/ Escaping from work with excellent excuses \\
\hline Sheep & Easily influenced and led by the pigs/ Stupid/ Victims \\
\hline
\end{tabular}

Table 2 represents the characteristics with which the animals are personified in English dictionaries, representing the English readers' expectations of the characteristics of the animals in $A F$, and the characteristics with which the animals are personified in Persian dictionaries and questionnaires, representing the Persian readers' expectations of the characteristics of the animals in $A F$. It should be noted that not all animals have special personifying characteristics. Therefore, if there are no personifying characteristics mentioned for an animal in the dictionary, you will see an empty slot illustrated by - in the table in front of the animal.

Table 2. Animals descriptive in English and Persian

\begin{tabular}{|c|c|c|}
\hline Animals & English Readers'́ Expectations & Persian Readers' Expectations \\
\hline Cat & $\begin{array}{l}\text { A spiteful gossipy woman/ Prostitute/ Sly/ } \\
\text { Resistant/ Curious/ Cautious/ Quick/ Of } \\
\text { sharp vision/ Of shining eyes/ Sleeping } \\
\text { lightly/ Symbol of liberty }\end{array}$ & $\begin{array}{l}\text { Untrustworthy/ Ungrateful/ Lecherous/ } \\
\text { Hypocritical/ Sly/ Lazy/ Cautious }\end{array}$ \\
\hline Chicken & $\begin{array}{l}\text { Timid/ Young/ Weak/ Shy/ Bad-tempered/ } \\
\text { Sleeping early }\end{array}$ & Timid/ Weak/ Small/ Juvenile \\
\hline Cow & $\begin{array}{l}\text { An untidy, obese, fertile, large, and } \\
\text { unattractive woman/ Stupid/ Of big eyes/ Of } \\
\text { innocent look }\end{array}$ & $\begin{array}{l}\text { Stupid/ Gluttonous/ Abundance/ Big/ Of big } \\
\text { eyes }\end{array}$ \\
\hline Dog & $\begin{array}{l}\text { Despicable/ An unattractive woman/ } \\
\text { Companionable/ Guard/ Bad-tempered/ } \\
\text { Wild/ Dirty/ Persistent/ Of long age }\end{array}$ & $\begin{array}{l}\text { Loyal, companionable/ Despicable/ Bad- } \\
\text { tempered/ Dirty/ Guard/ Resistant }\end{array}$ \\
\hline Donkey & Stupid/ Stubborn/ Hard-worker/ Patient & $\begin{array}{l}\text { Stupid \& Naïve/ Hard-worker, Load bearer/ } \\
\text { Stubborn/ Gluttonous/ Robust }\end{array}$ \\
\hline Duck & --------- & Good swimmer \\
\hline Duckling & --------- & Ugly \\
\hline Goat & Lascivious/ Humiliated/ Victim/ Stubborn & $\begin{array}{l}\text { Coward/ Blind Imitator, Obedient, Stupid/ } \\
\text { Agile \& Playful/ Humiliated/ Innocent }\end{array}$ \\
\hline Hen & $\begin{array}{l}\text { Maternal/ A busybody or gossipy woman/ } \\
\text { Sociable/ Submissive }\end{array}$ & $\begin{array}{l}\text { Maternal, Woman, Kind, Fertility/ Sleeping } \\
\text { early }\end{array}$ \\
\hline Horse & $\begin{array}{l}\text { Noble/ Hard-worker, a dependable, affective } \\
\text { worker (specially for a political party)/ } \\
\text { Ingenuous/ Strong/ Arrogance/ Swift/ } \\
\text { Uncultured/ Courageous/ Generous }\end{array}$ & $\begin{array}{l}\text { Noble/ Loyal/ Hard-worker, Load bearer/ } \\
\text { Gluttonous/ Strong/ Agile }\end{array}$ \\
\hline Mare & Woman/ Noble & Maternal, A loyal woman, Kind/ Noble \\
\hline Pigeon & $\begin{array}{l}\text { Harbinger of peace/ Gullible/ Love/ An } \\
\text { attractive girl/ Gentle/ Timid/ Jealous/ Of } \\
\text { protruding breast }\end{array}$ & $\begin{array}{l}\text { Dirty/ Lecherous/ Greedy \& Fat/ Powerful/ } \\
\text { Contemptible/ Wicked }\end{array}$ \\
\hline Pig & $\begin{array}{l}\text { Greedy and Fat/ Contemptible/ Filthy/ } \\
\text { Intelligent/ Imbecile/ Stubborn }\end{array}$ & $\begin{array}{l}\text { Messenger/ Love \& affection/ Harbinger of } \\
\text { peace/ Freedom/ Symbol of happiness/ A } \\
\text { beautiful girl }\end{array}$ \\
\hline Rabbit & $\begin{array}{l}\text { Fertile/ Docile/ Ingenuous/ Incompetent/ } \\
\text { Poor at sports, esp. golf, tennis or cricket/ } \\
\text { Fast }\end{array}$ & Intelligent/ Agile and Playful \\
\hline Rat & $\begin{array}{l}\text { Untrustworthy/ Informer/ Filthy/ Poverty/ } \\
\text { Timid/ Small/ Quiet/ Damaging / Disease } \\
\text { spreading }\end{array}$ & $\begin{array}{l}\text { Sly/ Dirty/ Small/ Destructive/ Timid/ } \\
\text { Untrustworthy, Informer }\end{array}$ \\
\hline Raven & Boastful/ Inauspicious/ Black & $\begin{array}{l}\text { Tale-bearer/ Ominous/ Sly/ Imitator/ Thief/ } \\
\text { Black }\end{array}$ \\
\hline Sheep & $\begin{array}{l}\text { Gullible/ Timid/ Docile/ Dependent/ } \\
\text { Vulnerable }\end{array}$ & $\begin{array}{l}\text { Sacrificial/ Easily led or influenced, Stupid, } \\
\text { Obedient, Simpleton, Innocent }\end{array}$ \\
\hline
\end{tabular}

\subsection{Data Analysis}

The characteristics attributed to the animals in $A F$ and their counterparts in the English and the Persian languages were compared and contrasted in order to discover whether the attributed characteristics of animals in these languages match with the characteristics of those animals in $A F$. 


\subsubsection{English Readers' Expectations and AF}

In the comparison of animals features in Orwell's novel with their collectively constructed figurative meaning in the English culture, the animals showed similar, different, opposite, or/and new characteristics. By new features, we mean those characteristics assigned to an animal in $A F$ which appear new to English readers, in regard to the images of animals conventionally identified in the metaphorical system of the English language. Of course, both sources ( $A F$ and the English language) also share some common features for the animal in question; otherwise, the features woud be considered different features, rather than new.

Table 3 summarizes which animals carry the same feature(s) in both $A F$ and English readers' minds and which ones do not. They are based on how the readers (of the ST or the TT), while reading $A F$, find the animals image: in line with their expectations; different from their expectations; counter to their expectations; or with some new qualities, ascribed to the animal in the ST.

Table 3. Animal personification in Animal Farm and in English readers'́ minds

\begin{tabular}{ccccc}
\hline Similar & Opposite & Different & New & Non-personified \\
\hline $\begin{array}{c}\text { Cat- Chicken- Cow- Dog- Donkey- } \\
\text { Duck- Duckling- Goat- Hen- Horse- } \\
\begin{array}{c}\text { Mare- Pig- Pigeon- Rat- Raven- } \\
\text { Sheep }\end{array}\end{array}$ & Donkey & Rabbit & Donkey & Duck \\
& & & Rat- Raven & Duckling \\
\hline
\end{tabular}

The animals in dark grey carry some similar and some different/new/opposite features. Duck and Duckling have been presented in light grey to indicate that they are, first and foremost, non-personified in the English language. Though, these animals carry some attributed features in AF: ducks are 'gregarious', 'victim', and 'non-intelligent'; ducklings are 'innocent' and 'unprotected children'. The animals in light grey, outwardly, indicate different or new images but, internally, point out implicit similarity, as the universal trait of the animal, like the case for duckling and duck; or one trait(s) implying the other(s), like chicken, which is the image of 'youth' in English, and the image of 'smallness' and 'weakness' in Animal Farm. This does not indicate this animal is associated with different metaphorical meanings in these sources; since the concept of 'youth' implies the two qualities of 'smallness' and 'weakness'.

Some animals are not fully metaphorized in the two sources similarly, seeing that some of them represent different picture(s) as well, such as donkey, rat, and raven.

\subsubsection{Persian Readers' Expectations and AF}

The same procedure was followed for Persian readers: how they construe animals in their culture and how they are introduced in $A F$ were compared and the results are presented below:

Table 4 illustrates which animals carry the same feature(s) in both $A F$ and English readers' minds and which ones do not.

Table 4. Animal personification in Animal Farm and in Persian readers'́ minds

\begin{tabular}{|c|c|c|c|c|}
\hline Similar & Opposite & Different & New & Non-personified \\
\hline $\begin{array}{c}\text { Cat- Chicken- Cow- Dog- Donkey- } \\
\text { Duck- Duckling- Goat- Hen- Horse- } \\
\text { Mare- Pig- Pigeon- Rat- Raven- } \\
\text { Sheep }\end{array}$ & Donkey & Rabbit & $\begin{array}{l}\text { Donkey } \\
\text { Duck- Hen } \\
\text { Horse- Mare }\end{array}$ & \\
\hline
\end{tabular}

\section{Discussion}

The above observations amount to an overall conclusive statement that in the source text $(A F)$ the animals have not been chosen arbitrarily. The majority of them have been chosen based on their particular image in the English language, since the characteristics attributed to the animals in the story conform to the English readers' expectations; that is, each animal plays that role in the story which conforms to the conventional meaning of that animal in the culture.

For the different cases, some of them could be explained and justified. For example, duck and duckling have no personifying characteristics in the English language as opposed to $A F$. Even though they are non-personified in the English language, the features of these two animals are not considered different or new images to English readers since the features are carried by the animal all over the world, resulting from its natural habits and traits. The Rats and the raven beside the characteristics that both $A F$ and the English sources share have got new features in $A F$; therefore, their personifying characteristics in $A F$ are new to English readers. It can be stated that giving new features to one character in a story is something ordinary in literary works. It is not unusual to give new characteristics to characters of stories, films, or plays. The new roles are always welcomed by the audience. In another way, assigning new characteristic(s) to one character of a story is considered a new role to him/her, rather a new personification.

Rabbits in AF are differently described from rabbits in the English culture: 'wild' and 'never tamed' in the former, and 'docile', 'ingenuous', 'incompetent', and 'poor at sports', in the latter. This kind of characterization is also identified as new roles appointed to the characters of the story.

For donkey, the situation is entirely different. It cannot be said, like the case of rats or raven, the animals have taken some new roles. For the donkey, the feature is absolutely opposite to the conventional attribution. Donkey has always 
been a stereotype of 'stupidity' in the English culture. The major characteristic of this animal in $A F$ is different, or more precisely, contradictory in their presentation to English readers; they are inconsistent with their expectations.

Regarding the animal in Persian culture and AF, as witnessed, in most cases, the characteristics attributed to the animals in $A F$ do not clash with Persian readers' expectations while reading the Persian translation of the story. The reason is that a) the features either result from the animal natural habits and traits, such as duck \& ducklings. A reader of the Persian translation of $A F$ understands and accepts the attributes particular to this animal in the book, since it describes the offspring of any creature, such as ducklings. b) Or some characteristics are not directly assigned to one animal but they can be implied or interpreted from the other explicit features of the animal; as mentioned for pig; its clever character in the story which is applied to follow its immoral purposes makes it the center of 'power' and 'wickedness', those features which are culturally constructed features of this animal in Persian.

For the animals donkey, duck, hen, horse, and mare, besides sharing some common features in the both sources in question, some new features are ascribed to them in the $A F$ which are new to the Persian readers. Hence, they are viewed as animals which have taken some new roles in this story.

Rabbit in Persian is 'intelligent', and 'playful'. In $A F$, it is personified as 'wild' and 'never tamed'; hence, it is also considered as a charater with new roles in this story.

It seems that the only animal upon which the Persian reader comes unexpectedly is the donkey. This animal with traits that are totally contrary to the readers' expectations may arouse some skepticism.

\section{Existing Translations of $\boldsymbol{A F}$}

It seems that, in his book $A F$, Orwell has not chosen even the names of the animals randomly but, as Meyers (1977) believes, with the purpose of them being compatible with their characteristics in the story (e.g. "Mollie", which signifies 'folly', is the name of one of the stupid mares; "Snowball" is one of the pigs which disappears in the story, like snow when it melts; or "Boxer" is the horse which, like a boxer, endures hardship and pain without quitting), the intention of selecting the animals based on their conventional pictures in one culture is not something to be ignored by the translator. The translator must care when choosing the animals in the TL in order that they reflect Orwell's intention in selecting those same animals.

As we checked the Persian translations of $A F$ we observed that the animals in all the translations are exactly the same animals as in Orwell's $A F$. The animals have been translated as follows (the order of animal is according to the order of their appearance in $A F)$ :

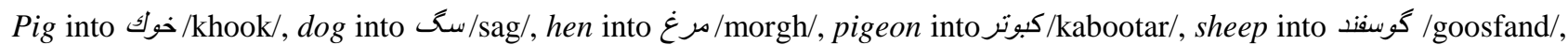

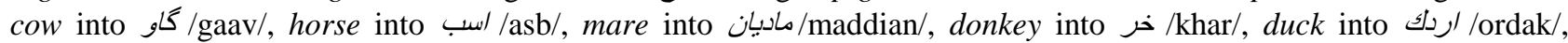

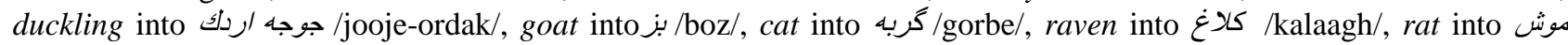

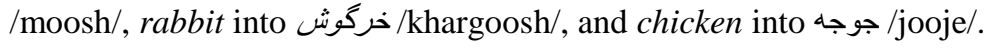

\section{Possible Methods of Translation of $A F$}

Cognitive translation of metaphor (Al-Hasnawi, 2007) recommends that the translator attempt to produce a similar metaphorical concept in the TT, and according to Gutt (2004), the translator should pave the way to matching the author's intention with the TT reader's expectation. The task becomes more complicated in translating $A F$, where in some cases the image of the animal is different even between the SL and the ST. Although the language is English, some unexpected differences (mentioned above) were observed between the characteristics of some animals in the story and their images in the English culture. The translator's effort cannot be focused only on finding an animal in the TL with the same image in the SL. These disparities require that the translation choices consider the relationship between the SL, the ST, and the TL. That is, the translator must reflect on three factors before rendering the animal terms: a) the features of the animal in the ST $(A F), \mathrm{b})$ the image of that animal in the SL (the English culture), and also c) its image in the TL (here, Persian). Hence, different cases of translation are involved and consequently different strategies are required.

We propose: a) if the animal attributes in $A F$ are found to match the norms of the English culture, in translating this animal into another language, no more consideration should be given; an animal term is selected in the target language which maps the same characteristics presented in the story for the animal; b) if the animal attributes in $A F$ are found to be contrary to the norms of the English culture, it is assumed that the author has intentionally attributed opposite characteristics to the animal, in this way floating the cultural construction of the metaphorical meaning, and this intention should not be violated by the translator and should be preserved. We can suggest, in the translation of this animal into another language, that an animal term should be selected in the target language which has the opposite metaphorical meaning to the norms of the target culture; c) if the animal attributes in $A F$ are found to be realized metaphorically different (not opposite) or new features, from what is expected by the English readers, they are considered as new roles ascribed to the animal; thus an animal term is selected in the target language which can match this situation or not be inconsistent with the expectations; and also d) those personified animals in the SL whose personifications are only the natural and innate features of the animal are kept in the translation.

To sum up, we reach to this conclusion that all animals can be kept the same in translation into the Persian language. The reasons are explained below in more details:

They represent the same image in the ST, the SL, and the TL (cat, chicken, cow, dog, duckling, goat, pig, pigeon, and sheep). 
Beside some similar features (in comparison with TL), they represent some new characteristics in the novel (donkey, duck, hen, horse, and mare).

$>$ The animal is intended to portrait a contradictory image in the text in comparison with its image in the culture (donkey).

$>$ The animal is intended to portrait a different image in the text in comparison with its image in the culture (rabbit).

$>$ Beside some similar features (in comparison with the SL), they represent some new characteristics in the novel (donkey, rat, and raven).

They are introduced in the novel according to their innate and inborn features (duck and duckling).

\section{Conclusion}

Animal Farm, in which all the characters (except the owners of the farms) are animals, were considered for this study. The goal was to examine whether or not the animals have been described in the ST according to their images in the SL, and if so, whether or not the current Persian translations of this novel have taken into consideration the probable difference in the images of the animals between the SL and the TL. We believed that, finding dissimilarities between the metaphorical meaning of animal terms in the SL and the TL, translators are expected to look for some translation strategies, like substitution or provision of brief explanations in footnotes or endnotes, with the purpose of contributing to the TT readers understanding of the author's intention in the planned choice of animal characters in the ST.

Apparently, all animals in $A F$ are sacrosanct; they seem unchangeable characters. It is unthinkable to change the animals in the original text for the other animals in the translation, because either each role is compatible with the natural and innate features of the animal or the author's intention in producing a case of attention and attraction is behind the reason for this choice. Orwell's intention behind the choice of the animals should not be violated. Any substitution of animal terms in $A F$ would lead to a literary disservice to both ST and the TT readers. The readers' "willing suspension of disbelief", a term suggested by Coleridge (1817, cited in Ortony, 1998), helps to accept some unusual ideas in order to be entertained by works of literature. Coleridge's theory of "willing suspension of disbelief" describes how people temporarily accept some unusual ideas and they are absorbed in literature in order to be entertained by works of literature. According to this theory, one willingly ignores the reality, since the limitations imposed by reality do not allow one to accept some readings. Forgetting the restrictions imposed by reality, one engages fully with the text so that she/he does not feel any anomaly in the text. Works of art imbue with a breakdown and disruption in social and logical norms in order to create strangeness and a new literary work and consequently to call attention to its novelties. We believe that the artistic creativity should not be overlooked in translation. The reader of $A F$ in his/her mother language, in which the animals are metaphorized and conceptualized differently, holds back his/her judgment about what he/she already knows about the animals' images in his/her culture and engages fully with the story so that she/he does not feel any absence or mismatch of norms in the text. The same situation should be prepared by the translator, by following the same strategy and observing this style of literature which has been set up by Orwell, closely and with sensitivity to all intended novelty and deviation from preconception, norms, and restrictions.

\section{Acknowledgement}

We would like to acknowledge Fundação para a Ciência e a Tecnologia (FCT) (Portugal) for granting the scholarship for carrying out the present paper.

\section{References}

Abdollahi, M. (2002). فرهنى نامه جانوران در /دب فارسى /farhangname-e janevaran dar adab-e farsi/ [Dictionary of animals in Persian literature]. Iran: Pazhoohande press.

Akhondi, A. A. (2004). (T.) قلعه حبو/نات /ghale-e heyvanat/ [the castle of animals]. [Online] Available: http://www.4shared.com/office/835Hn9ys/Animal_Farm_GHALE_HEYVANAT_.html

Al-Hasnawi, A. (2007). A cognitive approach to translating metaphors. Translation Journal, 11(3). [Online] Available: http://translationjournal.net/journal//41 metaphor.htm (Dec., 2009).

Amirshahi, A. (1982). (T.) قلعه حبو/نات/ghale-e heyvanat/. Tehran, Iran: Jami.

Catford, J. C. A. (1965). Linguistic theory of translation: An essay in applied linguistics. London: Oxford University Press.

Coleridge, S. T. (1817). Biographia literaria. [Online] Available: http://www.onlineliterature.com/coleridge/biographialiteraria//ebooks/6081 (Oct., 2013).

Dagut, M. (1987). More about the translatability of metaphor. Babel: International Journal of Translation 33(2), 77-84

Dagut, M. (1976). Can metaphor be translated? Babel: International Journal of Translation 32(1), 21-33.

Firoozbakht, M. (1992). (T.) قلعه حبوانات/ghale-e heyvanat/ [the castle of animals]. Tehran, Iran: Golshaee Press.

Gutt, E. A. (2004). Relevance theory and translation, paper presented at The 2004 International Meeting of the Society of Biblical Literature, 25-28, Jul, 2004.

Hall, E. T. (1976). Beyond culture. New York: Anchor press/Doubleday. 
Hatim, B. (1997). Communication across cultures: Translation theory and contrastive text linguistics. Exeter: University of Exeter Press.

Hiraga, M. K. (1991). Metaphor and comparative cultures. In P. G. Jr. Fendos (Ed.), Cultural communication: east and west (pp.140-66). Taiwan: Taiwan: T'ai Ch'eny Publishing Tainan.

Hosseini, S. \& Nabizade, M. (2003). (T.) مزرعه حيوانات /mazrae-e heyvanat/ [the farm of animals]. Tehran, Iran: Doostan.

Jadidi, A. \& Mohammadi Asiabi, S. (2004). (T.) قلعه حبوانات/ghale-e heyvanat/ [the castle of animals]. Tabriz, Iran: Akhtar.

Katan, D. (1999). Translating cultures: An introduction for translators, interpreters and mediators. Mancehster: ST Jerome Publishing.

Lakoff, G., \& Johnson, M. (1980). Metaphors we live by. Chicago: University of Chicago Press.

Maalej, Z. (2008). Translating metaphor between unrelated cultures: A cognitive perspective. Sayyab Translation Journal, (1), 61-82.

Mandelblit, N. (1995). The cognitive view of metaphor and its implications for translation theory. In M. Thelen and B. Lewandowska-Tomaszezylc (Eds.), Translation and meaning (pp. 483-95). Maastricht: Universitaire Press.

Mason, K. (1982). Metaphor and translation. Babel, 28, 140-149.

Meyers, J. (1977). A reader's guide to George Orwell. Lanham, Maryland: Littlefield Adams.

Moin, M. (Ed.) (1974). Dr. Moin's dictionary of Persian language. Tehran, Iran: Amirkabir press.

Newmark, P. (1980). The translation of metaphor. Babel 16(2), 93-100.

Nida, E. A. (2004). Principles of correspondence. In L. Venuti. (Ed.), The Translation Studies Reader (pp. 153-67). New York: Routledge.

Noorahmar, H. (1983). (T.) كزرعه حيوانات/mazrae-e heyvanat/ [the farm of animals]. Tehran, Iran: Marzban press.

Ortony, A. (1998). Metaphor and thought. (2nd ed.) Cambridge, England: Cambridge University Press.

Orwell, G. (1945). Animal farm. London, England: Secker and Warburg.

Oxford Advanced Learners' Dictionary. (1993). (2nd ed.) Oxford, England: Oxford University Press.

Palmatier, R. (1995). Speaking of animals: A dictionary of animal metaphors. San Francisco, USA: Greenwood Press.

Quinn, N. (1991). The cultural basis of metaphor. In J. W. Fernandez, Beyond metaphor: The theory of tropes in anthropology (pp. 57-93). Stanford: Stanford University Press.

Sadri Afshar, Gh., Hokmi, N., \& Hokmi, N. (1990). فرهنح زبان فارسى امروز /farhang-e zaban-e farsi-e emrooz/ [Dictionary of the modern Persian language]. Tehran, Iran: Kalame press.

Snell-Hornby, M. (1995). Translation studies: An integrated approach. Amsterdam: John Benjamins Publishing Company.

Toury, G. (2000). The nature and roles of norms in tanslation. In L. Venuti. (Ed.), The translation studies reader (pp. 198-211). London: Routledge.

Webster's Online Dictionary, Rosseta Edition. (2005). http://www.websters-online-dictionary.org/ 